\title{
Comunicação de Notícias Difíceis: Compartilhando Desafios na Atenção à Saúde
}

\author{
Breaking Bad News: Sharing Health Quare Challenges
}

Comunicación de Malas Noticias: Compartiendo Desafíos en la Atención a la Salud

\author{
Instituto Nacional de Câncer (INCA). Sociedade Beneficente Israelita Brasileira Albert \\ Einstein. \\ Rio de Janeiro: INCA, 2010. 206p. \\ ISBN: 978-85-7318-168-5
}

Taís Facina

Este livro, lançado em 2010 pelo Instituto Nacional de Câncer (INCA), é resultado de uma experiência inovadora reunindo grupos interdisciplinares de profissionais para a discussão de casos clínicos, baseada na formulação de Michel Balint, e tendo como tema central as dificuldades de comunicação de más notícias na prática clínica dos profissionais da saúde.

Tal experiência foi o Projeto Atenção ao Vinculo e Qualificação da Comunicação em Situaçóes Difíceis da Atenção Oncológica, uma parceria entre o Ministério da Saúde, por intermédio do INCA, e a Sociedade Beneficente Israelita Brasileira Albert Einstein. Esse programa abrange a rede de hospitais federais e universitários da cidade do Rio de Janeiro e é parte integrante das ações do HumanizaSUS, a Política Nacional de Humanização do Governo Federal que tem como objetivo efetivar os princípios do Sistema Único de Saúde (SUS).

A metodologia do projeto envolveu grupos multiprofissionais de trabalho, legitimando a criação de um espaço para a troca de experiências entre os profissionais em relação às dificuldades enfrentadas no dia a dia ao lidar com formas graves de adoecimento. Essa metodologia foi desenvolvida com o intuito de responder à demanda de produção de conhecimentos nessa área, resultando em um laboratório de práticas para beneficiar diretamente os profissionais envolvidos.

Foram 109 participantes, dos quais 54 médicos, 21 enfermeiros, 15 psicólogos, 13 assistentes sociais, quatro fisioterapeutas e dois nutricionistas, tanto do INCA como de serviços de oncologia de hospitais federais, hospitais universitários e institutos de ensino da rede de atenção oncológica e de cuidados paliativos do Rio de Janeiro.

E o livro foi desenvolvido nessa mesma lógica de trabalho, abordando a história e os fundamentos conceituais dessa experiência, relatando os temas trabalhados na dinâmica dos grupos de trabalho e as propostas apresentadas no encontro final.

São 206 páginas, divididas em três partes, com diversos artigos elaborados por diferentes participantes do projeto.

Na Parte I - Introdução, os coordenadores, observadores convidados e colaboradores apresentam o histórico e a concepção geral do Projeto e suas articulaçóes com a Política Nacional de Saúde do Trabalhador, com a Política Nacional de Humanização e com os recursos do Centro de Simulação Realística do Hospital Albert Einstein.

É apresentado um histórico da implantação do Projeto INCA de Humanização, relatando a mudança da atenção em oncologia rumo ao cuidado com o profissional da saúde e a uma gestáo compartilhada; as situações difíceis enfrentadas pelos profissionais na comunicação com os pacientes e familiares; e o uso do Protocolo SPIKES (uma metodologia para a comunicação de notícias difíceis desenvolvida pela Universidade do Texas/EUA e do Sunnybrook Regional Cancer Center, de Toronto/Canadá).

1'Jornalista, pós-graduada em "Produção do Livro", editora de publicaçôes científicas no Instituto Nacional de Câncer. 
Pela ótica dos serviços voltados para a saúde do trabalhador, é relatada a experiência da Divisão de Saúde do Trabalhador do INCA e as principais reinvidicaçôes desses profissionais no que diz respeito ao cuidado com sua integridade biopsicossocial, de forma a promover a minimizaçáo do sofrimento e o número de adoecimentos e afastamentos do trabalho.

Nesta primeira parte, são abordadas, ainda, as articulações do projeto com a Política Nacional de Humanização, alguns desdobramentos dessa iniciativa e uma proposta de multiplicação das Oficinas de Comunicação de Notícias Difíceis em unidades de saúde, além dos fundamentos teóricos que servem como base para a utilização da simulação realística como ferramenta de aprendizado e treinamento.

$\mathrm{Na}$ Parte II - Percurso dos Grupos, são desenvolvidos e aprofundados os principais temas surgidos e trabalhados nos grupos Balint-Paidéia, como a importância do enfoque interdisciplinar no trabalho de uma equipe de saúde, evidenciando como um cuidador mais consciente de si acaba modificando também a sua relaçáo com o paciente, gerando maior responsabilidade no tratamento e maior implicação com sua recuperação.

Há também um relato de caso clínico; os modelos assistenciais curativo - voltado para o tratamento da doença - e paliativo - que busca oferecer melhor qualidade de vida ao paciente quando se esgotam os recursos curativos; e a relevância dos aspectos afetivos envolvidos no relacionamento dos profissionais entre si e com os pacientes e familiares.

Outro assunto que mereceu destaque nesta parte do livro foi a especificidade do cuidado à criança e ao adolescente com câncer, pacientes que demandam uma dose intensa de afeto, sensibilidade e sinceridade na comunicação das difíceis notícias ao longo do tratamento.

Finalizando a Parte II está uma discussão sobre o papel e o lugar da interdisciplinaridade na comunicação de notícias difíceis no tratamento e a criação de um espaço de convivência para uma rede de solidariedade.

Na Parte III - Produção dos Grupos, são transcritas as apresentações que foram levadas e discutidas por todos os participantes no Encontro de Conclusōes e Propostas realizado ao final do Projeto. E logo após, como anexos, encontramos o Roteiro de Discussão, a Relação de Competências do Protocolo SPIKES, o Consenso SPIKES Jr. e a Relaçáo dos Participantes.

Como resultado, a experiência descrita no livro trouxe náo somente o relato e a análise de temas relevantes, mas também uma apurada produção teórica, baseada em uma transdisciplinaridade enriquecedora, tornando-se um valioso recurso para os profissionais da saúde que atuam com tais dificuldades. 